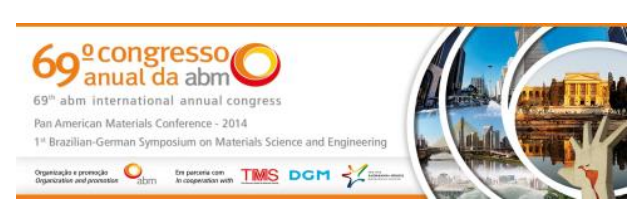

Tema: Materiais cerâmicos, compósitos e poliméricos

\title{
MICROESTRUTURA E PROPRIEDADES MAGNÉTICAS DA FERRITA Ni-Zn DOPADA COM SAMÁRIO*
}

\section{Resumo}

\author{
Raimison Bezerra de Assis ${ }^{1}$ \\ Flanelson Maciel Monteiro 2 \\ Samara Melo Valcacer ${ }^{3}$ \\ Ariadne de Souza Silva ${ }^{4}$ \\ Maurício Roberto Bomio Delmonte 5 \\ Carlos Alberto Paskocimas 6 \\ Rubens Maribondo do Nascimento ${ }^{7}$ \\ Uílame Umbelino Gomes ${ }^{8}$ \\ Fabiana Villela da Motta ${ }^{9}$
}

Ferritas são compostos cerâmicos que apresentam propriedades magnéticas, sendo estas dependentes da sua estrutura cristalina. Dentre as ferritas, a do tipo Ni-Zn é uma das mais promissoras, em virtude da microestrutura e das propriedades magnéticas deste material. Este trabalho teve como objetivo analisar a microestrutura e propriedades magnéticas da ferrita $\mathrm{Ni}-\mathrm{Zn}$ dopada com íons (TR) $\mathrm{Sm}^{3+}$. A ferrita $\mathrm{Ni}-\mathrm{Zn}-\mathrm{Sm}$ foi obtida pelo método dos precursores poliméricos, a partir da dissolução do ácido cítrico, nitrato de ferro, nitrato de níquel, nitrato de zinco, nitrato de samário e etilenoglicol. A resina obtida foi pirolisada a $350^{\circ} \mathrm{C} / 2 \mathrm{~h}$ com taxa de aquecimento de $10^{\circ} \mathrm{C} / \mathrm{min}$. e calcinada a $650^{\circ} \mathrm{C} / 3 \mathrm{~h}$ com taxa de aquecimento de $10^{\circ} \mathrm{C} / \mathrm{min}$. O material resultante foi caracterizado por difração de raios- $X$ (DRX), microscopia eletrônica de varredura (MEV) e magnetometria de amostra vibrante (VSM). Os resultados mostraram a formação de fase única da ferrita $\mathrm{Ni}-\mathrm{Zn}-\mathrm{Sm}$, com partículas aglomeradas e características magnéticas de material macio "soft", com baixa coercividade $(0,189 \mathrm{kOe})$ e magnetização de saturação $(47,699 \mathrm{emu} / \mathrm{g})$.

Palavras-chave:Ferrita; Ni-Zn-Sm; Propriedades magnéticas; Samário.

\section{MICROSTRUCTURE AND MAGNETIC PROPERTIES OF NI-ZN FERRITE DOPED WITH SAMARIUM}

\section{Abstract}

Ferrites are ceramic compounds which exhibit magnetic properties, which are dependent on its crystal structure. Among ferrites, the $\mathrm{Ni}-\mathrm{Zn}$ type is one of the most promising, due to the microstructure and the magnetic properties of this material. This work aimed to analyze the microstructure and magnetic properties of $\mathrm{Ni}-\mathrm{Zn}$ ferrite doped with ions (TR) $\mathrm{Sm}^{3+}$. The $\mathrm{Sm}-\mathrm{Ni}$ - $\mathrm{Zn}$ ferrite was obtained by polymeric precursors by dissolving citric acid, iron nitrate, nickel nitrate, zinc nitrate, samarium nitrate and ethylene glycol. The obtained resin was pyrolyzed at $350^{\circ} \mathrm{C} / 2 \mathrm{~h}$ with a heating rate of $10^{\circ} \mathrm{C} / \mathrm{min}$. and calcined at $650^{\circ} \mathrm{C} / 3 \mathrm{~h}$ with a heating rate of $10^{\circ} \mathrm{C} / \mathrm{min}$. The resulting material was characterized by X-ray diffraction (XRD), scanning electron microscopy (SEM) and vibrating sample magnetometry (VSM). The results showed the formation of single phase $\mathrm{Ni}-\mathrm{Zn}$ ferrite, $\mathrm{Sm}$, and agglomerated particles with magnetic properties of soft material "soft", low coercivity $(0,189 \mathrm{kOe})$ and saturation magnetization $(47,699 \mathrm{emu} / \mathrm{g})$.

Keywords: Ferrite; Ni-Zn-Sm; Magnetic properties; Samarium.

1 Tecnologia em Fabricação Mecânica, Mestre, Doutorando em Ciência e Engenharia de Materiais, Programa de Pós-graduação em Ciência e Engenharia de Materiais (PPGCEM), Universidade Federal do Rio Grande do Norte (UFRN), Natal, RN, Brasil.

2 Tecnologia em Fabricação Mecânica, Mestre, Professor de Eletromecânica, Instituto Federal de Educação, Ciência e Tecnologia da Bahia, Irecê, BA, Brasil.

3 Tecnologia em Materiais, Mestre, Doutoranda em Ciência e Engenharia de Materiais, PPGCEM, UFRN, Natal, RN, Brasil.

4 Engenheira Civil, Doutora, Pós-doutoranda, Laboratório de Materiais Cerâmicos e Metais Especiais (LMCME), UFRN, Natal, RN, Brasil.

5 Químico, Doutor, Professor, Depto. de Engenharia de Materiais, UFRN, Natal, RN, Brasil.

6 Engenheiro de Materiais, Doutor, Professor, Depto. de Engenharia de Materiais, UFRN, Natal, RN, Brasil.

7 Engenheiro Mecânico, Doutor, Professor, Depto. de Engenharia de Materiais, UFRN, Natal, RN, Brasil.

8 Físico, Doutor, Professor, Depto. de Física Teórica e Experimental, UFRN, Natal, RN, Brasil.

9 Engenheiro Químico, Doutora, Professora, Depto. de Engenharia de Materiais, UFRN, Natal, RN, Brasil.

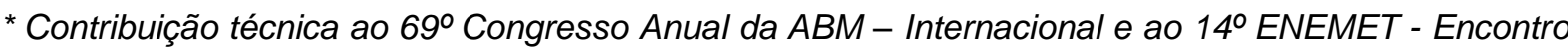
Nacional de Estudantes de Engenharia Metalúrgica, de Materiais e de Minas,21 a 25 de julho de 2014, São Paulo, SP, Brasil.
} 


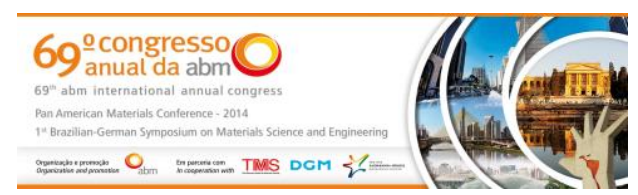

\section{INTRODUÇÃO}

Ferritas $\mathrm{Ni}-\mathrm{Zn}$ são materiais cerâmicos magnéticos mais versáteis e de uso abrangente, são materiais ferrimagnéticos conhecidos como macios ou moles "soft", na qual a sua estrutura cristalina é igual a do mineral espinélio $A_{3} \mathrm{O}_{4}$, que apresentam magnetização permantente espontânea [1-3]. Dentre a faixa de aplicação deste material, destacam-se dispositivos de baixa e alta freqüência, dispositivos de microondas, transformadores de potência, cabeçote de leitura/ gravação, dispositivo digital de alta velocidade entre outras. Características como elevada resistividade, baixas perdas dielétricas, baixas perdas por histerese e correntes parasitas (Foucault), altas densidades de fluxo de saturação, baixos campos coercitivos, alta permeabilidade magnética em altas frequências (10-500 $\mathrm{MHz}$ ), dureza mecânica, temperatura de Curie, elevada estabilidade química e custo relativamente baixo possibilitam essa gama de aplicação $[1,4]$.

As ferritas $\mathrm{Ni}-\mathrm{Zn}$ vêm sendo investigadas de forma minuciosa nas últimas décadas e muito tem sido divulgado no meio científico a respeito da importância destes materiais. Suas propriedades têm sido caracterizadas em relação a diversos fatores e sendo aperfeiçoadas com a aplicação de novas tecnologias que vêm descobrindo. Em relação às propriedades magnéticas das ferritas, a literatura demonstra que a permeabilidade magnética apresenta um valor constante até uma determinada freqüência, na qual acima desta a propriedade diminui rapidamente [5]. As ferritas da série níquel-zinco são materiais elétricos interessantes, reforçado por Brito [5] no qual afirmam que desde 1998, o mercado mundial de ferritas de estrutura de espinélio vem crescendo na ordem de $7 \%$ a.a., exigindo pesquisas de desenvolvimento de ferritas $\mathrm{Ni}-\mathrm{Zn}$ de alta performance.

Parâmetro importante para obtenção de ferritas com boas características microestruturais, morfológica e magnética é o tratamento térmico adotado. $\mathrm{O}$ tratamento em ferritas geralmente é feito em torno de $700-1000^{\circ} \mathrm{C}$ ao ar. Nas ferritas $\mathrm{Ni}$-Zn chega-se a alcançar total mudança da estrutura cristalina em espinélio em determinadas temperaturas de calcinação [6]. O tamanho de partícula influencia na conversão da estrutura de espinélio [7], pois os pós com partículas menores são mais reativos. Melhores propriedades magnéticas das ferritas, como a permeabilidade magnética, magnetização de saturação, coercividade entre outras, podem ser obtidas e ajustadas pela a adição de íons metálicos divalentes e/ou trivalentes [8]. Pesquisas vêm sendo desenvolvidas com o propósito de inserir cátions trivalentes de terras raras $\left(\mathrm{TR}^{3+}\right)$ na estrutura da ferrita, com o intuito de melhorar as propriedades magnéticas deste material.

Este trabalho teve como objetivo avaliar a microestrutura e as propriedades magnéticas da ferrita $\mathrm{Ni}-\mathrm{Zn}$ dopada com $\mathrm{Sm}^{3+}$ obtida pelo método dos precursores poliméricos.

\section{MATERIAIS E MÉTODOS}

Para sintetizar a ferrita de composição $\mathrm{Ni}_{0,7} \mathrm{Zn}_{0,23} \mathrm{Sm}_{0,07} \mathrm{Fe}_{2} \mathrm{O}_{4}$ pelo método dos precursores poliméricos, foram utilizados como reagentes de partida o ácido cítrico $\left(\mathrm{C}_{6} \mathrm{H}_{8} \mathrm{O}_{7}\right)$, nitrato de níquel $\left(\mathrm{Ni}\left(\mathrm{NO}_{3}\right)_{2} .6 \mathrm{H}_{2} \mathrm{O}\right)$, nitrato de zinco $\left(\mathrm{Zn}\left(\mathrm{NO}_{3}\right)_{2} .6 \mathrm{H}_{2} \mathrm{O}\right)$, nitrato de ferro $\left(\mathrm{Fe}\left(\mathrm{NO}_{3}\right)_{3} .9 \mathrm{H}_{2} \mathrm{O}\right)$, nitrato de samário $\left(\mathrm{Sm}\left(\mathrm{NO}_{3}\right)_{3} .9 \mathrm{H}_{2} \mathrm{O}\right)$ e etilenoglicol $\left(\mathrm{C}_{2} \mathrm{H}_{4}(\mathrm{OH})_{2}\right)$. O ácido cítrico $(\mathrm{AC})$ foi dissolvido na água $\left(60^{\circ} \mathrm{C}\right)$ a uma proporção 3:1 (AC: Metal), em seguida foram adicionados os nitratos metálicos: nitrato de ferro, nitrato de níquel, nitrato de zinco e nitrato de samário e por fim o poliálcool

\footnotetext{
* Contribuição técnica ao $69^{\circ}$ Congresso Anual da ABM - Internacional e ao 14ํㅡㄹ ENEMET - Encontro Nacional de Estudantes de Engenharia Metalúrgica, de Materiais e de Minas,21 a 25 de julho de 2014, São Paulo, SP, Brasil.
} 


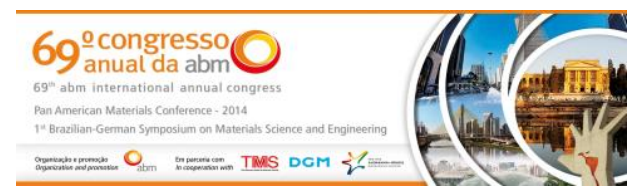

O parâmetro de rede (a) apresentado na Tabela 1 foi de 8,39 $\AA$, calculado a partir do software Unit Cell [9], assim como o volume da célula unitária $\left(591,60 \AA^{3}\right)$. 0 parâmetro de rede, o volume da célula unitária e a densidade em torno de 8,395 $\AA$, $591,60 \AA^{3}$ e $5,34 \mathrm{~g} / \mathrm{cm}^{3}$, respectivamente, estão de acordo com trabalhos reportados na literatura $[10,11]$.

Tabela 1. Padrões cristalográficos da ferrita Ni-Zn-Sm obtido por DRX.

\begin{tabular}{ccccc}
\hline Ferrita & $\delta(\mathrm{nm})$ & $\mathrm{a}(\AA)$ & $\begin{array}{c}\text { Vol. Cel. } \\
\text { Unit. }\left(\AA^{3}\right)\end{array}$ & $\begin{array}{c}\text { Densidade } \\
\left(\mathrm{g} / \mathrm{cm}^{3}\right)\end{array}$ \\
\hline $\mathrm{Ni}_{0,7} \mathrm{Zn}_{0,23} \mathrm{Sm}_{0,07} \mathrm{Fe}_{2} \mathrm{O}_{4}$ & 59,97 & 8,39 & 591,60 & 5,34 \\
\hline
\end{tabular}

A Figura 2 apresenta as micrografias da ferrita Ni-Zn-Sm, observa-se a influência de parâmetros como temperatura de calcinação na microestrutura do material, assim como no tamanho de cristalito e larga distribuição de partículas. Observa-se a formação de blocos porosos (não densos) oriundos do processo da calcinação (eliminação de material orgânico), com características irregulares, constituídas de aglomerados de partículas finas com porosidade interparticular. Esses blocos são definidos morfologicamente como aglomerados de características moles ou friáveis (constituídas de ligações fracas) e de fácil desaglomeração. Na Figura 2.a Observase placas com superfícies rugosas com partículas menores sobrepostas. A Figura 2.b. evidencia a formação de macroaglomerados de partículas nanométricas (inferiores a $100 \mathrm{~nm}$ ).
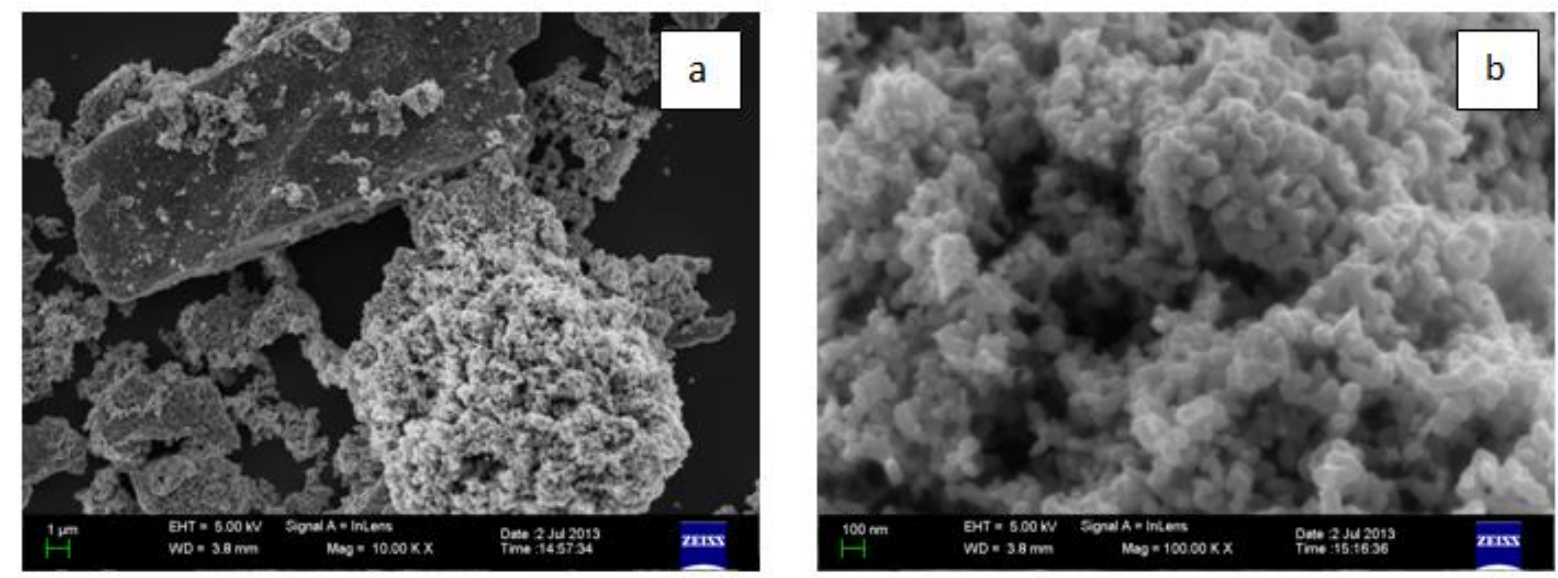

Figura 2. Micrografias obtidas por MEV - FEG da ferrita Ni-Zn-Sm.

Pode-se observar na Figura 3, um comportamento ferrimagnético da ferrita $\mathrm{Ni}_{0,7} \mathrm{Zn}_{0,23} \mathrm{Sm}_{0,07} \mathrm{Fe}_{2} \mathrm{O}_{4}$ calcinada a $650^{\circ} \mathrm{C} /$ 3h. A ferrita apresentou uma magnetização de saturação (Ms) de 47,699 emu/g, uma magnetização de remanência (Mr) de 9,734 emu/g e coercividade $(\mathrm{Hc})$ de 0,189 $\mathrm{KOe}$, caracterizando o material como magnético mole ferrimagnético. O comportamento e as propriedades magnéticas podem ser atribuídas a distribuição uniforme de íons $\mathrm{Fe}^{3+}$ nos sítios tetraédricos $(A)$ e octaédricos (B), em que cancelam os momentos magnéticos e a magnetização total, e ao adicionar íons $\mathrm{Ni}^{2+}$ (magnético), $\mathrm{Zn}^{2+}$ e $\mathrm{Sm}^{3+}$ com preferências nos sítios octaédricos e tetraédricos da rede, respectivamente, provocam o deslocamento dos íons $\mathrm{Fe}^{3+}$ da posição tetraédrica aumentando a magnetização dos sítios octaédricos, alterando os seus momentos

\footnotetext{
* Contribuição técnica ao $69^{\circ}$ Congresso Anual da ABM - Internacional e ao 14ํㅡㄹ ENEMET - Encontro Nacional de Estudantes de Engenharia Metalúrgica, de Materiais e de Minas,21 a 25 de julho de 2014, São Paulo, SP, Brasil.
} 


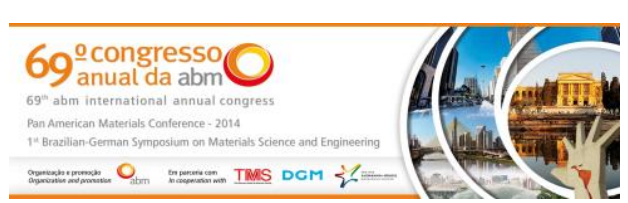

magnéticos. Além disso, os valores de magnetização de saturação (Ms), magnetização de remanência (Mr) e campo coercivo $(\mathrm{Hc})$ podem está atribuídas a estequiometria do material, visto que a inserção do terra rara $\left(\mathrm{Sm}^{3+}\right)$ na ferrita $\mathrm{Ni}-\mathrm{Zn}$ influencia na distorção da rede cristalina cúbica e como conseqüência o comportamento magnético do material.

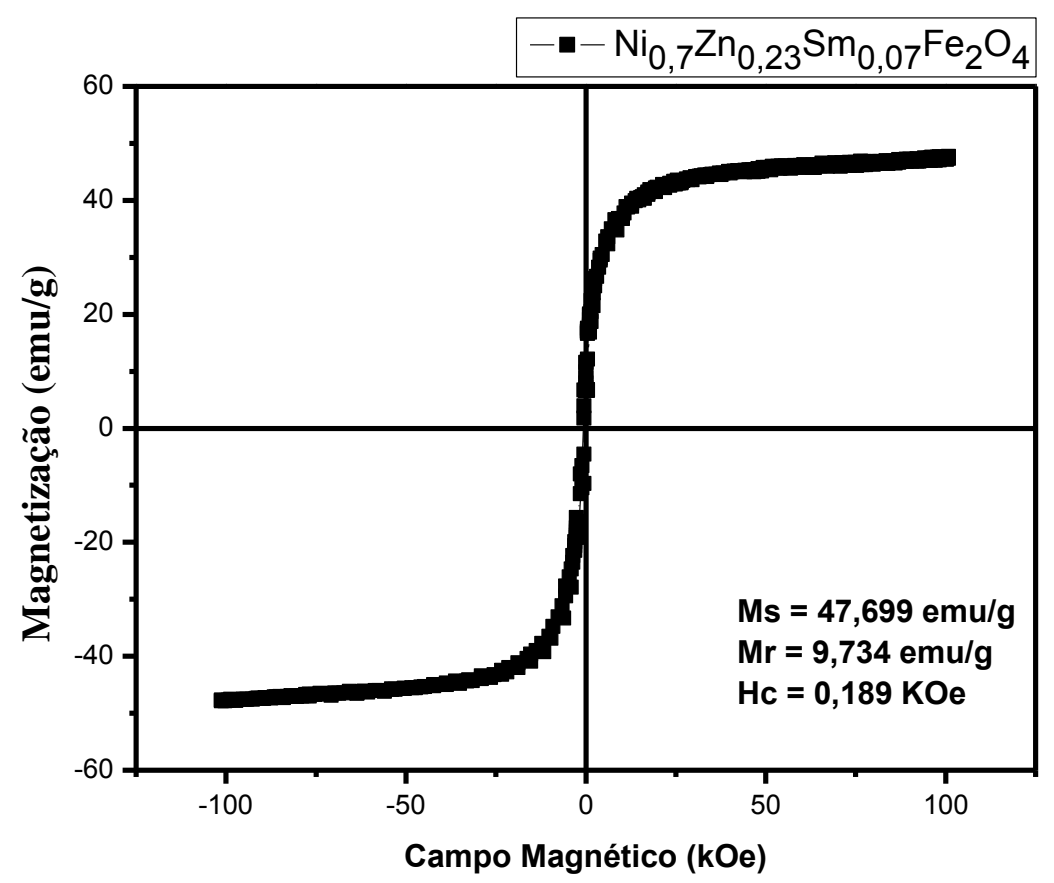

Figura 3. Curva de histerese magnética da ferrita Ni-Zn-Sm.

Estudos realizados por Zhiyuan [12] confirmam a influência da estequiometria e da microestrutura nas propriedades magnéticas das ferritas, sendo a coercividade influenciada estequiometria e a magnetização de saturação influenciada pela microestrutura. Partículas nanométricas apresentam características que potencializam o aumento da magnetização de saturação. Através das curvas de histereses, observa-se um comportamento magnético de ferritas moles "soft", em que a magnetização não é permanente, no qual magnetiza e desmagnetiza com facilidade, concordando com os resultados de Pinho [13].

\section{CONCLUSÃo}

As características extrínsecas dos pós obtidos pelo método dos precursores poliméricos como tamanho de partículas, morfologia, grau de aglomeração e a temperatura de calcinação afetaram de forma significativa o comportamento magnético das ferritas $\mathrm{Ni}-\mathrm{Zn}-\mathrm{Sm}$, bem como a dopagem do íons terras raras $\mathrm{Sm}^{3+}$. A partir das características microestruturais e magnéticas da ferrita $\mathrm{Ni}-\mathrm{Zn}-\mathrm{Sm}$, este material apresenta ser promissor na aplicação de diversos componentes e dispositivos com aspectos de materiais magnéticos moles.

\section{Agradecimentos}

Os autores agradecem a CAPES, CNPq e ao Programa de Pós-graduação em

* Contribuição técnica ao $69^{\circ}$ Congresso Anual da ABM - Internacional e ao 14ํㅡㄹ ENEMET - Encontro Nacional de Estudantes de Engenharia Metalúrgica, de Materiais e de Minas,21 a 25 de julho de 2014, São Paulo, SP, Brasil. 
Ciência e Engenharia de Materiais (PPGCEM/ UFRN) pelos auxílios e recursos financeiros.

\section{REFERÊNCIAS}

1 Yadoji P. et al. Microwave sintering of $\mathrm{Ni}-\mathrm{Zn}$ ferrites: comparison with conventional sintering. Materials Science and Engineering. 2003; B98: 269-278, 2003.

2 Grunberger W. et al. Rubber bonded ferrite layer as a microwave resonant absorber in a frequency range from 3 up to $16 \mathrm{GHz}$. J. Magn. Magn. Mater. 1991; 101: $173-174$.

3 Gupta SC; Agrawa NL. Broad band thin sheet absorbers for S-; C-; X- and Kubands. J. IETE. 1993; 39: 197-200.

4 Rahimi M. et al. The effect of zinc doping on the structural and magnetic properties of $\mathrm{Ni}_{1-x} \mathrm{Zn}_{x} \mathrm{Fe}_{2} \mathrm{O}_{4}$. J Mater Sci. 2013; 48: 2969-2976.

5 Brito VLO. Ferritas Ni-Zn: breve revisão sobre o processo convencional de fabricação e as propriedades permeabilidade magnética e constante dielétrica. Cerâmica. 2006; 52 : 221-231.

6 Reynolds III TG; Buchanan RC. Ceramic Materials for Electronics - Processing, Properties, and Applications, Marcel Dekker Inc. New York: Buchanan (Ed.), 1991.

7 Magee JH. et al. Ferrites: Proc. Int. Conf., Japan, 217, 1970.

8 Sveum L. K. and Mo S. Cation order in Solution-Synthesized Ferrites. Ceramic Transactions. 1995; 47: 305-310.

9 UNITCELL-97 program [T.J.B Holland, S.A.T. Redfem, Unit cell refinement from powder diffraction data: the use of regression diagnostics, Miner. Mag. 61(1997) 65-67].

10 Kothawale MM. et al. Characterization and Magnetic Properties of Nanoparticle $\mathrm{Ni}_{1-x} \mathrm{Zn}_{\mathrm{x}} \mathrm{Fe}_{2} \mathrm{O}_{4}$ Ferrites Prepared Using Microwave Assisted Combustion Method. Journal Supercond Nov Magn. 2012; 25: 1907-1911.

11 Olhero SM. et al. Co-precipitation of a Ni-Zn ferrite precursor powder: Effects of heat treatment conditions and deagglomeration on the structure and magnetic properties. Journal of the European Ceramic Society. 2012; 32: 2469-2476.

12 Zhiyuan L.; Maoren X.; Qingqiu Z. Effects of iron deficiency on magnetic properties of $\left(\mathrm{Ni}_{0.76} \mathrm{Zn}_{0.24}\right) \mathrm{O}\left(\mathrm{Fe}_{2} \mathrm{O}_{3}\right)_{0.575}$ ferrite. Journal of Magnetism and Magnetic Materials. 2000; 219: 9-14.

13 Pinho MS. et al. Performance of radar absorbing materials by waveguide measurements for X and Ku-band frequencies. Eur. Polymer J. 2002; 38 (11): 2321 2327.

\footnotetext{
* Contribuição técnica ao $69^{\circ}$ Congresso Anual da ABM - Internacional e ao 14ํㅡㄹ ENEMET - Encontro Nacional de Estudantes de Engenharia Metalúrgica, de Materiais e de Minas,21 a 25 de julho de 2014, São Paulo, SP, Brasil.
} 